\title{
Down-regulation of FAK and IAPs by laminin during cisplatin-induced apoptosis in testicular germ cell tumors
}

\author{
MAOULANA ANDJILANI ${ }^{1,2}$, JEAN-PIERRE DROZ ${ }^{1,2}$, MOHAMED BENAHMED ${ }^{2}$ and ERIC TABONE ${ }^{1,2}$ \\ ${ }^{1}$ Centre Régional Léon Bérard, 28 rue Laënnec, 69373 Lyon; ${ }^{2}$ INSERM U407, \\ Faculté de Médecine Lyon-Sud, BP 12, 69621 Oullins, France
}

Received May 13, 2005; Accepted June 23, 2005

\begin{abstract}
The purpose of this present study was to investigate the role of inhibitor of apoptosis proteins (IAPs), their inhibitor, Smac, and the focal adhesion kinase (FAK) in the laminin enhancement of cisplatin-induced apoptosis in a testicular tumor germ cell line, NCCIT. We demonstrated that specifically in laminin-adherent NCCIT cells, cisplatininduced apoptosis followed a significant decrease of c-IAP-2 protein expression and of both XIAP mRNA and protein expression. Smac expression was not modified in any tested conditions. We also found that FAK, which mediates the ECM-integrin antiapoptotic signal was down-regulated early in cells cultured on laminin. Our results provide a possible mechanistic explanation to cisplatin-induced apoptosis in NCCIT cells adhered on laminin. Cisplatin down-regulated FAK protein expression early, which therefore failed to activate c-IAP-2 and XIAP expression, resulting in a defect in the abrogation of the activation of caspases. Thus, the laminin signaling enhances the cisplatin-induced apoptosis, at least partly, through a down-regulation of survival signal molecules. Our data raise an interesting possibility that a therapeutic strategy targeting these survival molecules would be efficient to overcome chemo-resistance in testicular germ cell tumor.
\end{abstract}

\section{Introduction}

Testicular germ cell tumors (TGCTs) are the most common malignancies among young men. Fortunately, these tumors

Correspondence to: Dr Eric Tabone, Centre Régional Léon Bérard, Département d'Anatomie et de Cytologie Pathologiques, 28 rue Laënnec, 69373 Lyon, Cedex 08, France

E-mail: tabone@lyon.fnclcc.fr

Abbreviations: TGCT, testicular germ cell tumor; ECM, extracellular matrix; BSA, bovine serum albumin; FBN, fibronectin; FAK, focal adhesion kinase; XIAP, X-linked inhibitor of apoptosis protein; IAP, inhibitor of apoptosis protein

Key words: apoptosis, laminin, testicular tumors, cisplatin, integrin, IAPs, FAK are curable even in an advanced stage, by cisplatin-based chemotherapy, with an overall cure rate of approximately $80 \%(1,2)$.

In a few cases, however, resistance occurs. Although, a large number of research has been conducted concerning cisplatin, at present, to our knowledge, little is known about the molecular mechanisms by which cisplatin induces cancer cell death. However, it is now well established that cisplatin exerts its cytotoxic action through induction of apoptosis, at least in TGCT cells (3-6).

Apoptosis is a genetically encoded, ubiquitous pathway enabling cells to undergo highly regulated death in response to pro-death signaling. The deregulation of this tightly regulated process leads to disastrous consequences, and is involved in many diseases, such as cancer, infertility, autoimmunity and neurodegeneration. The family of caspase cysteine proteases is the core of the apoptotic machinery that irreversibly commits a cell to die. When a cell receives a signal to die, specific caspases become activated in a hierarchical fashion that leads to the processing and activation of several critical effector caspases which cleave structural proteins and repair enzymes necessary for cellular homeostasis (7-9).

One mechanism that is used to control caspase activity is the expression of endogenous protease inhibitors. The foremost example is a family of caspase inhibitors known as inhibitor of apoptosis proteins (IAPs). The IAPs were originally described as an activity that prevents apoptotic cell death caused by multiple triggers in Drosophila, Caenorhabditis elegans and mammalian cells (10-12). Subsequently, several studies demonstrated, by in vitro assays, that IAPs act as direct inhibitors for caspases. Specifically, three mammalian IAPs: c-IAP1, c-IAP2, and XIAP, are direct inhibitors of recombinant caspases-3, -7 , and -9 . This is generally accepted to be the principal mechanism for the antiapoptotic activity of the IAPs in various experimental settings $(12,13)$.

Furthermore, integrins are known to transduce signals that modulate anticancer drug (including cisplatin)-induced apoptosis in many cell types (14-19). Integrins are a family of heterodimeric $(\alpha \beta)$ transmembrane cell surface receptors that mediate cell-cell adhesion as well as cell-extracellular matrix (ECM) contacts and then play a key role in normal and tumor cell behavior (20-24).

Focal adhesion kinase (FAK) is an intracellular nonreceptor protein tyrosine kinase important for ECM-integrin signaling. On association with integrin, FAK is auto or 
Table I. Primer sequences, PCR conditions and products.

\begin{tabular}{|c|c|c|c|c|}
\hline Gene & Primer sequences & $\operatorname{Tm}\left({ }^{\circ} \mathrm{C}\right)$ & Product (bp) & Cycles \\
\hline \multirow[t]{2}{*}{ c-IAP-1 } & R: 5'-CTgTCACCTACTCATgCAC-3' & 57 & 123 & 33 \\
\hline & F: 5'-TgTTTgTTgCTgTTTgTCC-3' & & & \\
\hline \multirow[t]{2}{*}{ c-IAP-2 } & R: 5'-TAATACCgggAACATgAAg-3' & 62 & 188 & 25 \\
\hline & F: 5'-ggACACTGATCAAAAAAAgAC-3' & & & \\
\hline \multirow[t]{2}{*}{ XIAP } & R: 5'-ACTATgCTCACCTAACCCC -3' & 55 & 281 & 30 \\
\hline & F: 5'-CCgTgCTTCATAATCTgCC -3' & & & \\
\hline \multirow[t]{2}{*}{ Smac/Diablo } & R: 5'-ggTCTTTCAgAgATggCAgC-3' & 57 & 147 & 29 \\
\hline & F: 5'-CAgCTTggTTTCTgCTTTCC-3' & & & \\
\hline \multirow[t]{2}{*}{ FAK } & R: 5'-CTTCTgCAgTTTCCCCAgAg-3' & 62 & 200 & 32 \\
\hline & F: 5'-CCAggTggTTggCTCACTAT-3' & & & \\
\hline \multirow[t]{2}{*}{ B2 $\mu$ globulin } & R: 5'-CCATgATgCTgCTTACATgTCTCTgATCC-3' & $55-62$ & 374 & $25-32$ \\
\hline & F: 5'-gAgARgTCTCgCTCCgTggCCTTAgC-3' & & & \\
\hline
\end{tabular}

transphosphorylated and activated (25-28). Activated FAK mediates antiapoptotic signal via its binding to other transduction molecules required for the activation of Ras mitogenactivated protein kinase (MAPK) (27). Moreover, the cisplatininduced apoptosis depends on integrin-mediated activation of MEK and ERK, two members of the mitogen-activated protein kinase (MAPK) family $(29,30)$. Overexpression of FAK protects cells against various apoptotic stimuli by up-regulating IAP gene expression (31). FAK is proteolytically cleaved by caspase-3 during the cisplatin-induced apoptosis (32).

In a previous study, we have shown that laminin- $\alpha 6$ integrin signaling enhances cisplatin-induced apoptosis by stimulating the activation of the two effector caspases- 3 and -6 , in a testicular tumor germ cell line, NCCIT (19).

In the present study, our interest focused on the regulation of the mammalian inhibitors of apoptosis, c-IAP-1, c-IAP-2 and XIAP. Our findings showed that on laminin but not on any other tested substratum, cisplatin down-regulated c-IAP-2 protein and both, XIAP mRNA and protein expression. This IAPs down-regulation occurred after an early decrease of FAK. The expression of Smac/Diablo, an inhibitor of IAPs, was not modified in any tested condition. Taken together, the data presented here substantiate a model whereby laminin enhances cisplatin-induced apoptosis through the abrogation of the survival signal mediated by FAK.

\section{Materials and methods}

Cell culture. NCCIT is a human testicular embryonic carcinoma cell line obtained from the American Type Culture Collection. These TGCT (testicular germ cell tumor) adherent cells were grown in RPMI-1640 medium (Invitrogen Corp., UK) supplemented with $15 \%$ fetal bovine serum (SVF, Life technology, Germany). They were maintained at $37^{\circ} \mathrm{C}$ in a $5 \% \mathrm{CO}_{2}$ atmosphere.
Coating and cytotoxicity assay. Plates coated with ECM protein or adhesion molecules were formed by incubating 12-well plastic tissue culture plates with $8 \mu \mathrm{g} / \mathrm{cm}^{2}$ laminin-1 (SigmaAldrich, L'Isle D'Abeau, FR); $5 \mu \mathrm{g} / \mathrm{cm}^{2}$ fibronectin (SigmaAldrich) or $10 \mathrm{mg} / \mathrm{cm}^{2}$ heat-denatured BSA (Sigma-Aldrich) for $2 \mathrm{~h}$ at $37^{\circ} \mathrm{C}$. The plates were then rinsed with $1 \mathrm{X}$ PBS and blocked with heat-denatured BSA $(2 \mathrm{mg} / \mathrm{ml})$ for an hour. The plates were then twice rinsed with $1 \mathrm{X}$ PBS, and cells $\left(2 \times 10^{5}\right.$ per well) were seeded onto these plates and incubated at $37^{\circ} \mathrm{C}$ in $5 \% \mathrm{CO}_{2}$.

Cells from the exponential culture phase were treated with $10 \mu \mathrm{M}$ cisplatin [cis-platinum (II) diamine dichloride, DDP] (Merck, Lyon, FR) for $4 \mathrm{~h}$, washed with fresh culture medium and incubated in cisplatin-free medium. Following 48-h incubation, attached and floating cells were collected, pooled and suspended in $1 \mathrm{X}$ PBS and then cytocentrifugated (300 g, $5 \mathrm{~min}$ ) on adhesive slides. They were immediately fixed and apoptosis detection assay was performed.

Kinetic studies in cisplatin-treated NCCIT cells. NCCIT cells grown on laminin, BSA or fibronectin until exponential culture phase (control) were treated with cisplatin as indicated above. At $0,12,24$ and $48 \mathrm{~h}$ after the end of the treatment, cells were collected and total RNA and proteins were extracted for RT-PCR and Western blot analysis.

Total RNA extraction. Cells were harvested, washed in cold phosphate-buffered saline (PBS), and lysed immediately in TRIzol reagent, a monophasic solution of phenol and guanidine isothiocyanate (Invitrogen, Groningen, NL). This reagent is an improvement on the single-step RNA isolation method developed by Chomczynski and Sacchi (33). The quality of extracted total RNA was checked by spectrophotometry (ratio A260/A280) and 1\% agarose gel electrophoresis. The amount of RNA was estimated by spectrophotometer at $260 \mathrm{~nm}$. 


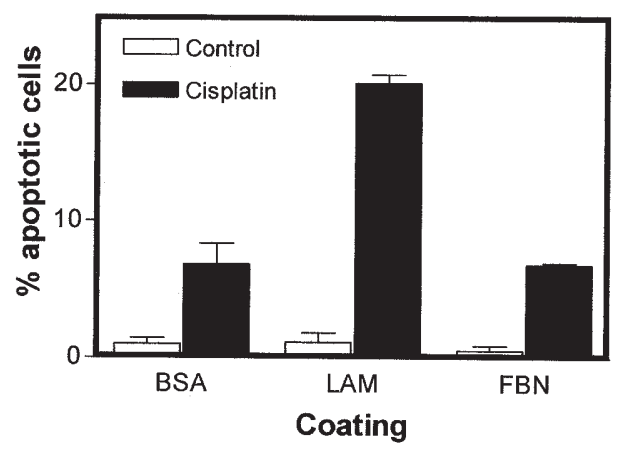

Figure 1. Extracellular matrix protein modulation of NCCIT cell sensitivity to cisplatin-induced apoptosis. The number of apoptotic cells was determined by TUNEL assay $48 \mathrm{~h}$ after the end of $4 \mathrm{~h}$ of cisplatin $(10 \mu \mathrm{M})$ treatment of NCCIT cells grown on either BSA, laminin (LAM) or fibronectin (FBN).

Semi-quantitative co-amplified RT-PCR. cDNAs were generated from reverse transcription (RT) of $2 \mu \mathrm{g}$ of total RNA using random hexanucleotides as primers $(50 \mu \mathrm{M})$ in presence of dNTP $250 \mu \mathrm{M}$; (Invitrogen, Groningen, NL), dithiothreitol (DTT, $10 \mu \mathrm{M}$ ) and Moloney murine leukemia virus (MMLV) reverse transcriptase $(10 \mathrm{U} / \mu \mathrm{l})$ for $1 \mathrm{~h}$ at $37^{\circ} \mathrm{C}$.

cDNAs were co-amplified (IAP-1, IAP-2, XIAP, Smac and FAK with $B 2$ microglobulin) by PCR with Taq polymerase $(0.05 \mathrm{U} / \mu \mathrm{l})$, deoxynucleotides $(50 \mu \mathrm{M}), 0.75 \mu \mathrm{Ci}\left(\alpha^{-3} \mathrm{P}\right)$ deoxyATP, specific primers $(1 \mu \mathrm{M})$ or $\beta 2$ microglobulin primer $(0.4$ or $0.2 \mu \mathrm{M}$ ). The mixture was first heated at $95^{\circ} \mathrm{C}$ for $5 \mathrm{~min}$ and then $\mathrm{X}$ cycles of $95^{\circ} \mathrm{C}$ for $30 \mathrm{sec}$, Tm (melting temperature) for $30 \mathrm{sec}, 72^{\circ} \mathrm{C}$ for $30 \mathrm{sec}$, then $72^{\circ} \mathrm{C}$ for $5 \mathrm{~min}$ (Table I). PCR products were analyzed on an $8 \%$ polyacrylamide gel. Dried gels were exposed to Cyclone ${ }^{\mathrm{TM}}$ storage phosphor screen for $30 \mathrm{~min}$. Intensities of autoradiographic bands were estimated by densitometric scanning using OptiQuant software (Packard Instrument Company, Inc., Meriden, USA). The data were expressed as interest gene: $\$ 2$ microglobulin mRNA ratios. PCR amplified products were checked by direct sequencing (ABI PRISM; 310 genetic Analyzer; Applied Biosystems, Courtaboeuf, FR).

Western blot analysis. NCCIT cells were harvested using Trypsin-EDTA (Invitrogen, Groningen, NL) and pelleted by centrifugation at $300 \mathrm{~g}$ for $5 \mathrm{~min}$. Whole cell protein extracts were prepared by addition of cold lysis buffer on pelleted cells. Lysis buffer consists of $50 \mathrm{mM}$ Tris (pH 7.4), $250 \mathrm{mM}$ $\mathrm{NaCl}, 5 \mathrm{mM}$ EDTA and $50 \mathrm{mM} \mathrm{NaF}$ supplemented immediately before use with a cocktail of protease inhibitors (Sigma-Aldrich). The protein concentration of cell lysates was determined using a colorimetric Bradford method.

Proteins (30-60 $\mu \mathrm{g}$ ) were resolved by $12 \%$ SDS-PAGE and electro-blotted onto nitrocellulose membranes in transfer buffer (25 mM Tris, $185 \mathrm{mM}$ glycine containing 20\% Methanol). The transfer was performed at a constant voltage of $100 \mathrm{~V}$ for $1 \mathrm{~h}$. The membrane was blocked by soaking in PBS, $0.05 \%$ Tween-20 and 5\% non-fat dried milk for an hour at room temperature. Then the membranes were rinsed three times with PBS $/ 0.05 \%$ Tween-20 and incubated overnight at $4{ }^{\circ} \mathrm{C}$ with primary antibodies raised against IAP-1 (rabbit polyclonal; Santa Cruz Biotechnology, CA), IAP-2 (rabbit polyclonal;
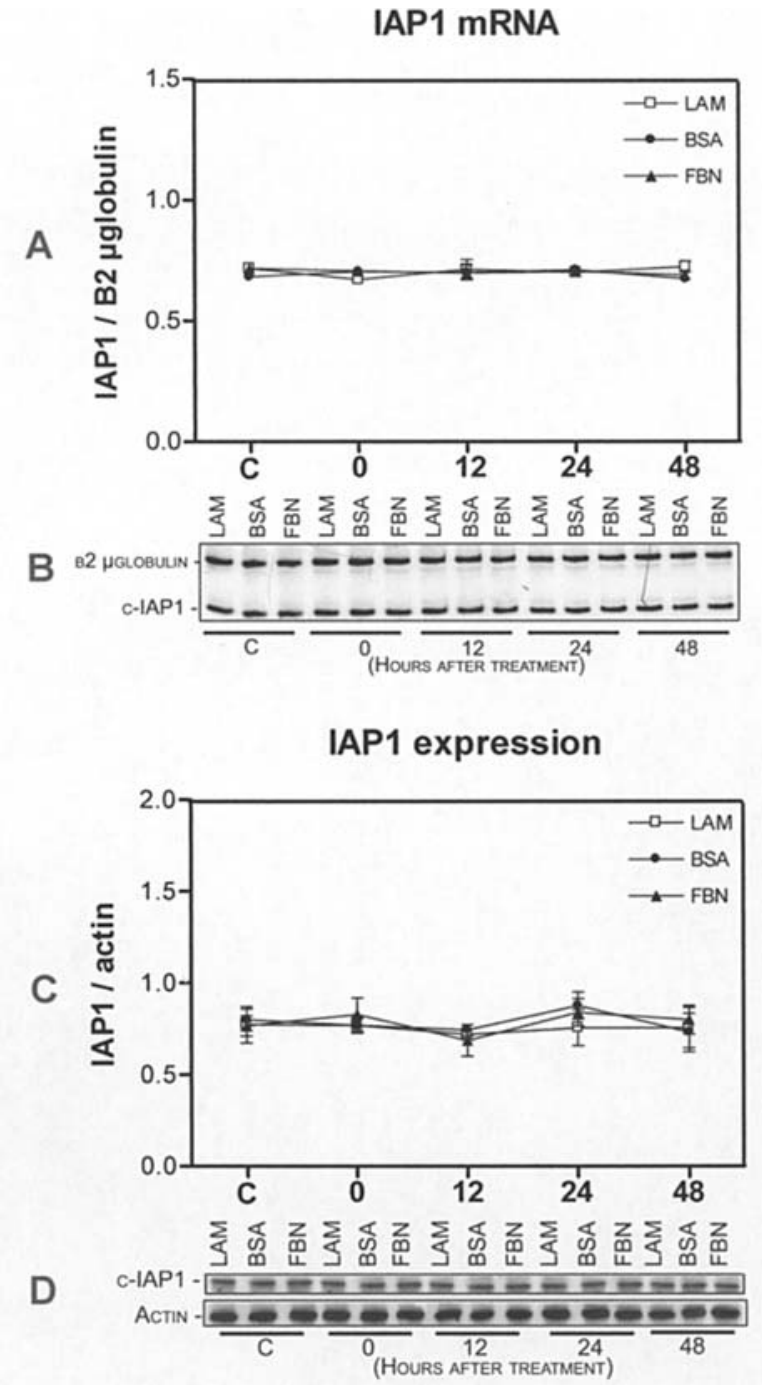

Figure 2. c-IAP1 mRNA and protein levels. c-IAP1 mRNA (A) and protein (C) levels were determined in untreated control cells (C) and at 0, 12, 24, and $48 \mathrm{~h}$ after the end of cisplatin treatment of NCCIT cells cultured on laminin (LAM), BSA, and fibronectin $(\mathrm{FBN})$. The values represent the means $\pm \mathrm{SD}$ determined from at least four independent experiments. Representative blots of these experiments are shown (B and D).

Santa Cruz Biotechnology), XIAP (rabbit monoclonal; Sigma-Aldrich), Smac/Diablo (goat polyclonal; Santa Cruz Biotechnology) and FAK (goat polyclonal; Santa Cruz Biotechnology). Antibodies were respectively diluted at 1:200, 1:200, 1:100, 1:100 and 1:200 in PBS containing 1\% blocking reagent (non-fat dried milk). Membranes were rinsed three times with PBS/0.05\% Tween-20 and then incubated with horseradish peroxidase-labeled goat or rabbit antibodies $(1: 3000)$. Bound antibodies were detected by chemiluminescence using a Covalab kit and Hyperfilm ${ }^{\mathrm{TM}}$ ECL $^{\mathrm{TM}}$ (Amersham Pharmacia Biotech). The blots were reprobed with an anti-actin antibody, 1:4000 diluted (Sigma-Aldrich). The data were expressed as protein level:B-actin level ratio.

Statistical analysis. Data represent the means of at least four independent experiments. Statistical significance was determined by One-way ANOVA with Dunnett's post-test using Prism version 3.03 (GraphPad Software Inc., San Diego, CA). Differences were accepted as significant at $\mathrm{p}<0.05$. 


\section{IAP2 mRNA}

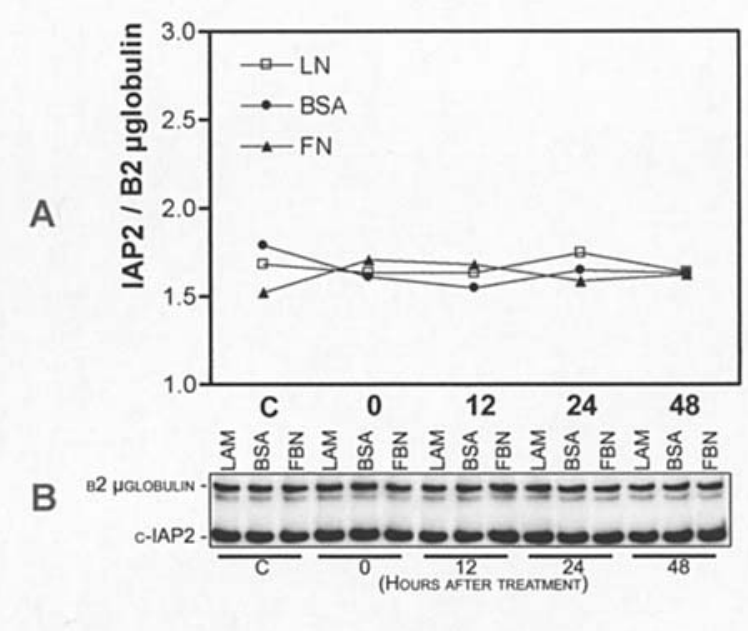

IAP 2 expression

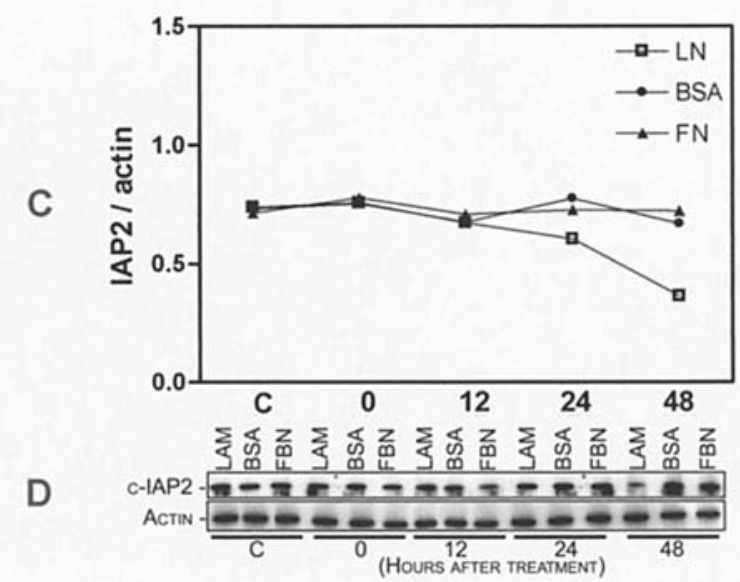

Figure 3. c-IAP2 mRNA and protein levels. c-IAP2 mRNA (A) and protein (C) levels were determined in untreated control cells (C) and at $0,12,24$, and $48 \mathrm{~h}$ after the end of cisplatin treatment of NCCIT cells cultured on laminin (LAM), BSA, and fibronectin (FBN). The values represent the means \pm SD determined from at least four independent experiments. Representative blots of these experiments are shown (B and D)

\section{Results}

Effect of ECM proteins in cisplatin-induced apoptosis. Fortyeight hours after the end of the $10 \mu \mathrm{M}$ cisplatin treatment, apoptotic cells were quantified using the in situ TUNEL method (Fig. 1). NCCIT cells cultured on either bovine serum albumin (BSA)- or fibronectin (FBN)-coated plates displayed a low percentage (7\% and $9 \%$ ) of apoptotic cells. However, when cultured on laminin (LAM)-coated plates, the percentage of NCCIT apoptotic cells was significantly $(\mathrm{p}<0.001)$ higher (20\%) compared to treated cells cultured on the other substrata. Untreated cells cultured on laminin as well as cells plated on the other substrata did not undergo apoptosis, showing less than $1 \%$ of apoptotic cells.

Expression of IAP-1 $\mathrm{mRNA}$ and protein. In cisplatin-treated NCCIT cells cultured on laminin, BSA or fibronectin, semiquantitative co-amplification RT-PCR and Western blot analyses were performed at $0,12,24$ and $48 \mathrm{~h}$ after the end of the cisplatin treatment. As compared to untreated control
XIAP mRNA

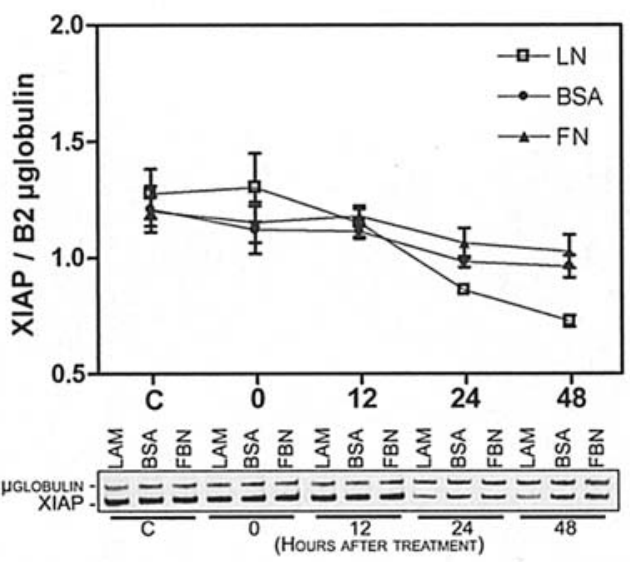

XIAP expression

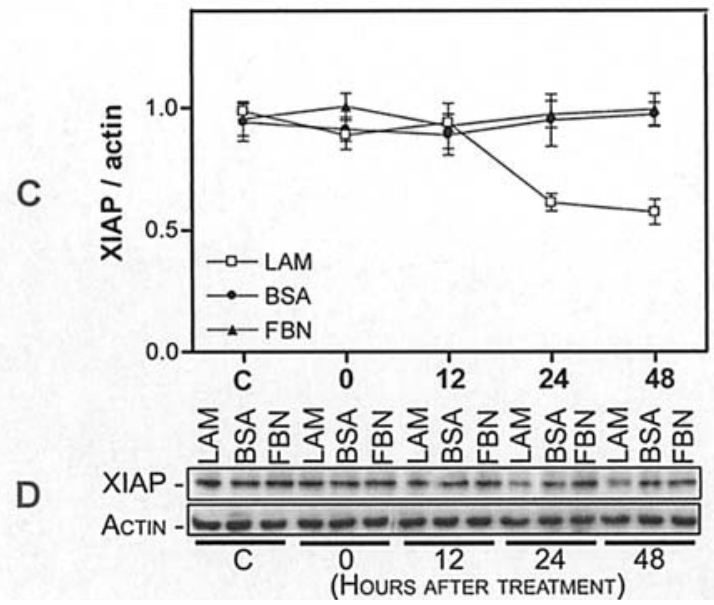

Figure 4. XIAP mRNA and protein levels. XIAP mRNA (A) and protein (C) levels were determined in untreated control cells (C) and at $0,12,24$, and $48 \mathrm{~h}$ after the end of cisplatin treatment of NCCIT cells cultured on laminin (LAM), BSA, and fibronectin (FBN). The values represent the means \pm SD determined from at least four independent experiments. Representative blots of these experiments are shown (B and D).

cells, both IAP-1 mRNA (Fig. 2A and B) and protein (Fig. 2C and D) expression levels did not change after cisplatin treatment. Therefore, no significant difference was observed, whatever the substrate on which NCCIT cells were cultured, either in treated or untreated cells.

Expression of IAP-2 $m R N A$ and protein. IAP-2 mRNA expression was not modified either by the cisplatin treatment or by the substratum. We observed an equal amount of IAP-2 mRNA level (Fig. 3A and B) in all tested conditions. In contrast, at 24 and $48 \mathrm{~h}$ after the end of the cisplatin treatment, IAP-2 protein level was significantly decreased $(\mathrm{p}<0.05)$ in NCCIT cells cultured on laminin, as compared to NCCIT cells cultured on BSA or fibronectin (Fig. 3C and D), which displayed a high amount of IAP-2 protein until at least $48 \mathrm{~h}$ post cisplatin treatment.

Expression of XIAP mRNA and protein. We further investigated the XIAP mRNA and protein expression. As shown in Fig. 4A and $\mathrm{B}$, XIAP mRNA expression decreased after cisplatin 


\section{Smac mRNA}
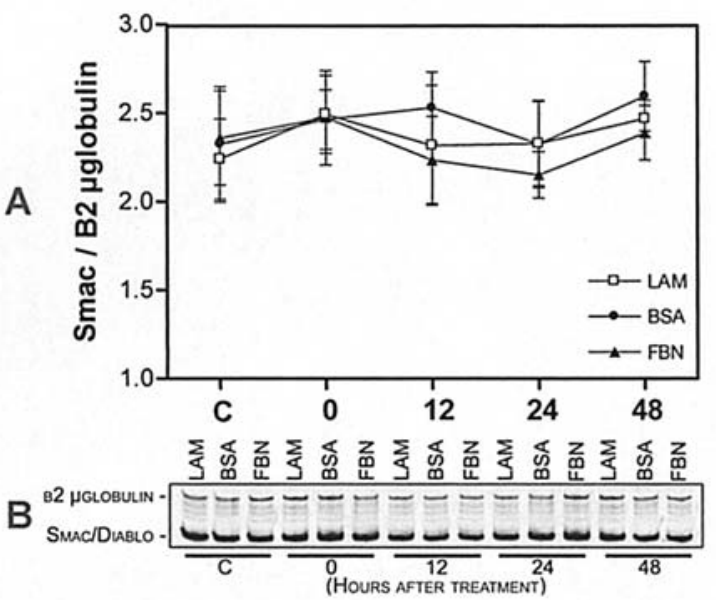

Smac/Diablo expression

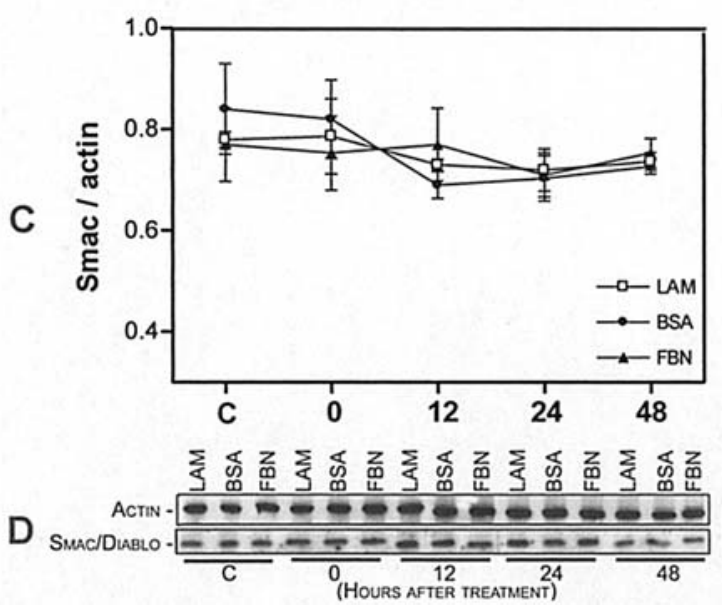

Figure 5. Smac/Diablo mRNA and protein levels. Smac/Diablo mRNA (A) and protein $(\mathrm{C})$ levels were determined in untreated control cells $(\mathrm{C})$ and at $0,12,24$, and $48 \mathrm{~h}$ after the end of cisplatin treatment of NCCIT cells cultured on laminin (LAM), BSA, and fibronectin (FBN). The values represent the means \pm SD determined from at least four independent experiments. Representative blots of these experiments are shown (B and D).

treatment in NCCIT cells cultured on laminin, BSA or fibronectin. At $48 \mathrm{~h}$ after the end of cisplatin treatment in NCCIT cells grown on laminin-coated plates, XIAP mRNA was significantly low $(\mathrm{p}<0,01)$, as compared to cells cultured on BSA or fibronectin. On laminin, $24 \mathrm{~h}$ after cisplatin treatment, the decrease of XIAP mRNA was significantly different, as compared to NCCIT cells cultured on BSA but its level was similar to that observed on fibronectin-seeded cells.

The amount of XIAP protein significantly decreased $(\mathrm{p}<0.05)$ at 24 and $48 \mathrm{~h}$ post cisplatin treatment in NCCIT cells cultured on laminin whereas in BSA or fibronectin its level remained elevated in all tested conditions (Fig. 4C and D).

Expression of Smac mRNA and protein. The expression of a second mitochondrial activator of caspases, known as Smac/DIABLO, was evaluated in NCCIT cells cultured on laminin, BSA or fibronectin and treated with cisplatin. The various substrata (laminin, BSA or fibronectin) did not modify Smac/DIABLO mRNA expression. Furthermore, Smac mRNA
FAK mRNA

A

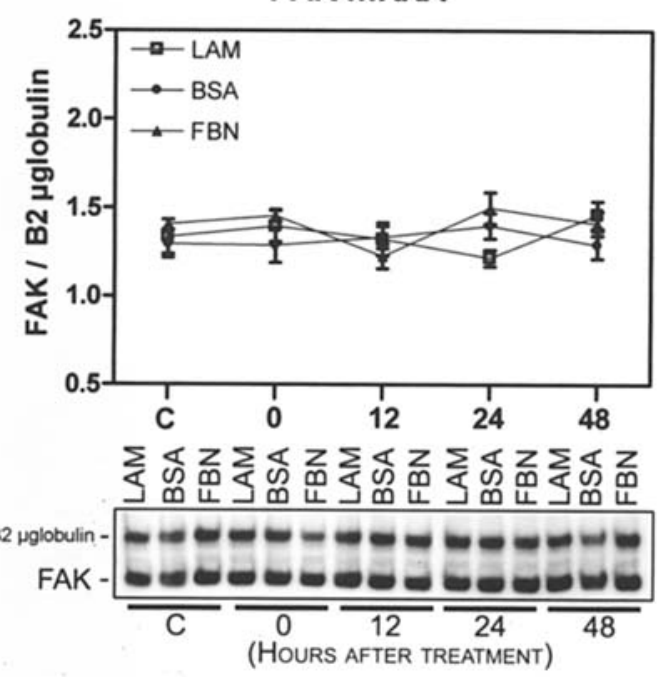

FAK expression

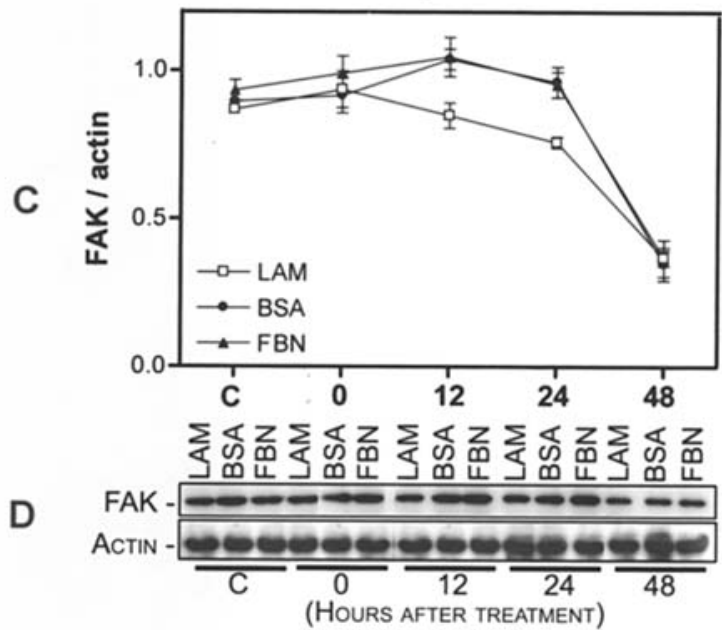

Figure 6. FAK mRNA and protein levels. FAK mRNA (A) and protein (C) levels were determined in untreated control cells (C) and at $0,12,24$, and $48 \mathrm{~h}$ after the end of cisplatin treatment of NCCIT cells cultured on laminin $(\mathrm{LAM}), \mathrm{BSA}$, and fibronectin $(\mathrm{FBN})$. The values represent the means $\pm \mathrm{SD}$ determined from at least four independent experiments. Representative blots of these experiments are shown (B and D).

was expressed in equal amounts in untreated control cells (C) and in cisplatin-treated NCCIT cells (Fig. 5A and B). Also, as indicated in Fig. $5 \mathrm{C}$ and $\mathrm{D}, \mathrm{Smac} / \mathrm{DIABLO}$ protein expression was not modified, either by cisplatin treatment or by the substratum.

Expression of FAK mRNA and protein. Both the mRNA and protein expression profiles of focal adhesion kinase (FAK) were determined using semi-quantitative RT-PCR and Western blot analysis respectively. Data represented in Fig. 6A and B clearly indicate that focal adhesion kinase mRNA expression was not modified by either the substrata (laminin, BSA or fibronectin) or cisplatin treatment.

Analysis of whole cell extracts by Western blotting (Fig. 6C and D) indicated that untreated control cells (C) grown on laminin, fibronectin or BSA displayed no significant difference in p125 FAK protein expression. Cisplatin treatment 
dramatically decreased the amount of p125 FAK at $48 \mathrm{~h}$ after the end of treatment. At $48 \mathrm{~h}$ after treatment, we observed a low level FAK protein in the three tested conditions. Interestingly, in NCCIT cells cultured on laminin, the level of p125 FAK protein was significantly decreased $(\mathrm{p}<0.05)$ at 12 and $24 \mathrm{~h}$ after the end of cisplatin treatment whereas, in this space of time, in NCCIT cells cultured on BSA or fibronectin, the amount of p125 FAK protein remained as elevated as in untreated control cells. When NCCIT cells were adhered on laminin, cisplatin-induced p125 FAK protein expression decrease occurred earlier than in cells cultured on fibronectin or BSA.

\section{Discussion}

We showed here, in agreement with our previous study (19), that NCCIT cells, which are basically moderately cisplatinsensitive in standard culture conditions (34), exhibited a significantly higher sensitivity to cisplatin when cultured on laminin as compared to cells grown on BSA or fibronectin. Untreated NCCIT cells adherent on laminin did not undergo apoptosis, suggesting that the induction of apoptosis is not a direct effect of laminin but rather a promotion or a facilitation of the cisplatin-induced apoptosis in these TGCT cells.

We further examined the regulation of the inhibitors of apoptosis, c-IAP-1, c-IAP-2 and XIAP, in this laminin enhancement of cisplatin-induced apoptosis in testicular germ cell tumors (TGCTs) since many reports have demonstrated that the overexpression of XIAP, c-IAP1 and c-IAP2 suppresses the apoptosis induced by a variety of stimuli, including tumor necrosis factor (TNF), Fas, menadione, staurosporin, etoposide, Taxol, and growth factor withdrawal (10,35). Moreover, IAPs block chemotherapy-induced apoptosis in various experimental models (12). Several studies have also shown that these three mammalian apoptosis inhibitor proteins (IAPs), c-IAP1, c-IAP2, and XIAP, function as direct inhibitors for specific caspases $(13,36)$.

We found here that the levels of both c-IAP-1 mRNA and protein expressed in NCCIT cells remained unchanged after cisplatin treatment on laminin, BSA or fibronectin. This result suggests that c-IAP-1 is not involved in laminin facilitation on NCCIT cell sensitivity to cisplatin.

We further investigated c-IAP-2 expression which is known to display similar properties to c-IAP-1 for inhibition of caspases (13). The c-IAP-2 mRNA level was not modified either in untreated or treated NCCIT cells on all tested substrata. However, whereas c-IAP-2 protein level was not modified in cisplatin-treated NCCIT cells cultured on fibronectin or BSA, at $48 \mathrm{~h}$ after the end of cisplatin treatment, the amount of c-IAP-2 protein was significantly decreased when NCCIT cells were seeded on laminin. The downregulation of this key apoptosis inhibitor protein was correlated with an increase of apoptosis, implying that c-IAP-2 acts at a central point in cisplatin-induced apoptosis signaling in NCCIT cells cultured on laminin.

Recent reports have shown that cisplatin-induced apoptosis was accompanied by a decrease in the amount of XIAP in human ovarian and prostate cancer cells (37-39). XIAP is the most potent inhibitor of caspases among human IAP family proteins $(13,35,40,41)$ and it is reported to be highly expressed in same human cancers $(39,42)$. Interestingly, our results showed that cisplatin-induced apoptosis followed a significant inhibition of XIAP mRNA and protein expression in NCCIT cells adherent on laminin. This phenomenon was time and substratum dependent. Then, at 24 and $48 \mathrm{~h}$ after cisplatin treatment, when NCCIT cells were grown on laminin but not the other substrata (fibronectin or BSA), the XIAP mRNA and protein significantly decreased. The decrease of XIAP may, at least partly, contribute to the higher sensitivity to cisplatin observed in NCCIT cells cultured on laminin. In agreement with previous reports, which have demonstrated that cisplatin-induced apoptosis required the inhibition of XIAP expression $(37,38,43)$, our data strongly indicated that the modulation of XIAP expression and/or stability could be one of the mechanisms by which laminin signaling enhances the cisplatin-induced apoptosis in the testicular tumor cell line, NCCIT.

A second mitochondria activator of caspases known as Smac/Diablo has been shown to antagonize IAP protein and then eliminate their survival signal. In the cytosol, Smac/Diablo amplifies caspase activation by binding IAPs via its aminoterminal Reaper motif, leading to displacement of IAPs from caspases (44-47). In NCCIT cells the levels of Smac/DIABLO mRNA and protein remained unchanged in all tested conditions. Thus, in this model, Smac/DIABLO is not implicated in the observed increase in number of apoptotic cells induced by cisplatin when NCCIT cells adhered on laminin.

Altogether, our findings give new insights into the mechanism by which cisplatin may induce apoptosis in tumor cells. An inhibition of two relevant apoptosis inhibitors (c-IAP-2 and XIAP) occurs before cisplatin-induced apoptosis in NCCIT cells cultured on laminin. The IAPs are direct inhibitors of both caspases-3, -7 and -9 (48). Especially, it is known that the third BIR domain of XIAP mediates binding and inhibition of caspase-9. Caspase- 9 is one of the bestcharacterized initiator caspases, it plays an important role in apoptosis and directly activates the effector caspases, -3 and -7 . At the basal state, both the procaspase- 9 zymogene and the processed caspase- 9 exist mostly as a monomer. These monomers have the potential to be activated by the apoptosome complex or inhibited by XIAP. To fulfill its initiator function, caspase-9 needs to be activated, which requires its homodimerization. Interaction with the third BIR domain of XIAP prevents the homodimerization and activation of caspase- 9 $(36,45,49)$. Consequently, although cleaved caspase-9 level was high in cisplatin-treated NCCIT cells (19), only cells cultured on laminin displayed a high level of processed caspase- 3 and a concomitant high number of apoptotic cells. Thus, the cisplatin-induced down-regulation of XIAP in cells grown on laminin could result in failure to block caspase-9 activation and then the activation of effector caspase-3. Nevertheless, the cross-talk between laminin- $\alpha 6$ integrin signaling and cisplatin-induced apoptosis cascade that promotes such a pro-apoptotic signal remains to be elucidated.

Cisplatin-induced apoptosis is believed to be cell-density dependant (50), although the precise mechanism of this phenomenon and the effect of cisplatin on cell adhesion are not fully understood. The non-receptor protein kinase FAK is believed to be important for integrin-mediated cell adhesion. It has been demonstrated that FAK suppresses anchorage- 
dependent apoptosis (51) and that inhibition of FAK induces apoptosis (52). FAK is cleaved by caspases during the induction of apoptosis (53). Therefore, it has been demonstrated that caspase-3 mediates FAK cleavage during cisplatininduced apoptosis but XIAP overexpression protects the cell from FAK processing after cisplatin treatment $(32,54)$. In NCCIT cells, we observed in all substrata that FAK protein level was significantly low at $48 \mathrm{~h}$ after the end of cisplatin treatment as compared to untreated control cells. Such decrease was concomitant with an increase of cisplatin-induced apoptosis in a substrata-dependant manner. When NCCIT cells were cultured on laminin where they displayed the higher sensitivity to cisplatin, the decrease in the amount of FAK protein began early at 12 and $24 \mathrm{~h}$ after the end of the cisplatin treatment whereas, in the meantime on fibronectin or BSA, FAK protein remained highly expressed. Moreover, the decrease of FAK protein level observed in NCCIT cells adhered on laminin was followed by a dramatic decrease of XIAP and c-IAP-2 expression and, therefore, caspase-3 activation. These results suggest that the down-regulation of the upstream survival signal protein FAK early after cisplatin treatment can cause a defect in XIAP gene expression as suggested by others (31). Thus, cisplatin may abrogate integrin survival signal mediation by FAK in NCCIT cells cultured on laminin and then facilitate NCCIT cells undergoing the death process and subsequent caspase activation. Further studies may determine the mechanism leading to the early FAK protein down-regulation in cisplatin-treated NCCIT cells. Our results suggest that it could be independent of the caspase- 3 cleavage process commonly accepted to explain this phenomenon $(32,39)$.

In conclusion, our findings provide a possible molecular mechanistic explanation of the laminin- $\alpha 6$ integrin signaling enhancement of cisplatin-induced apoptosis. We clearly showed that on laminin, cisplatin early induced a downregulation of FAK, the principal protein mediating integrin survival signaling. Therefore, it could lead to the decrease of IAP expression observed on treated cells adhered on laminin, and consequently the increase of apoptosis and the subsequent caspase activation.

These findings raise the interesting possibility to develop a powerful therapeutic strategy coupling the inhibition of IAPs and cisplatin treatment to overcome chemo-resistance.

\section{Acknowledgements}

This study was supported by the Institut National de la Santé et de la Recherche Médicale and by the Ligue Nationale Contre le Cancer, Comité Départemental de l'Ain, France. Maoulana Andjilani is a recipient of a grant from the Collectivité Départementale de Mayotte.

\section{References}

1. Bosl GJ and Motzer RJ: Testicular germ-cell cancer. (Review) [122 refs]. N Engl J Med 337: 242-253, 1997.

2. Dearnaley D, Huddart R and Horwich A: Regular review: managing testicular cancer. Br Med J 322: 1583-1588, 2001.

3. Huddart RA, Titley J, Robertson D, Williams GT, Horwich A and Cooper CS: Programmed cell death in response to chemotherapeutic agents in human germ cell tumour lines. Eur J Cancer [A] 31A: 739-746, 1995.
4. Raaphorst GP, Mao J, Yang H, et al: Evaluation of apoptosis in four human tumour cell lines with differing sensitivities to cisplatin. Anticancer Res 18: 2945-2951, 1998.

5. Mueller T, Voigt W, Simon H, Fruehauf A, Bulankin A, Grothey A and Schmoll HJ: Failure of activation of caspase-9 induces a higher threshold for apoptosis and Cisplatin resistance in testicular cancer. Cancer Res 63: 513-521, 2003.

6. Pommier Y, Sordet O, Antony S, Hayward RL and Kohn KW: Apoptosis defects and chemotherapy resistance: molecular interaction maps and networks. Oncogene 23: 2934-2949, 2004.

7. Herr I and Debatin KM. Cellular stress response and apoptosis in cancer therapy. Blood 98: 2603-2614, 2001.

8. Degterev A, Boyce M and Yuan J: A decade of caspases. Oncogene 22: 8543-8567, 2003.

9. Holdenrieder S and Stieber P: Apoptotic markers in cancer. Clin Biochem 37: 605-617, 2004

10. Liston P, Roy N, Tamai K, et al: Suppression of apoptosis in mammalian cells by NAIP and a related family of IAP genes. Nature 379: 349-353, 1996.

11. Deveraux QL, Takahashi R, Salvesen GS and Reed JC: Xlinked IAP is a direct inhibitor of cell-death proteases. Nature 388: 300-304, 1997

12. Deveraux QL and Reed JC: IAP family proteins-suppressors of apoptosis. Genes Dev 13: 239-252, 1999.

13. Roy N, Deveraux QL, Takahashi R, Salvesen GS and Reed JC: The c-IAP-1 and c-IAP-2 proteins are direct inhibitors of specific caspases. EMBO J 16: 6914-6925, 1997

14. Aoudjit F and Vuori K: Integrin signaling inhibits paclitaxelinduced apoptosis in breast cancer cells. Oncogene 20: 4995-5004, 2001.

15. Rintoul RC and Sethi T: Extracellular matrix regulation of drug resistance in small-cell lung cancer. Clin Sci 102: 417-424, 2002.

16. Sherman-Baust CA, Weeraratna AT, Rangel LB, et al: Remodeling of the extracellular matrix through overexpression of collagen VI contributes to cisplatin resistance in ovarian cancer cells. Cancer Cell 3: 377-386, 2003.

17. Sato K, Katagiri K, Hattori S, Tsuji T, Irimura T, Irie S and Katagiri T: Laminin 5 promotes activation and apoptosis of the T cells expressing alpha3beta1 integrin. Exp Cell Res 247: 451-460, 1999.

18. Terui Y, Furukawa Y, Sakai T, et al: Up-regulation of VLA-5 expression during monocytic differentiation and its role in negative control of the survival of peripheral blood monocytes. J Immunol 156: 1981-1988, 1996.

19. Andjilani M, Droz JP, Benahmed M and Tabone E: $\alpha 6$ integrin subunit mediates laminin enhancement of cisplatin-induced apoptosis in testicular tumor germ cells. Int J Cancer (In press).

20. Juliano RL and Haskill S: Signal transduction from the extracellular matrix. J Cell Biol 120: 577-585, 1993.

21. Howe A, Aplin AE, Alahari SK and Juliano RL: Integrin signaling and cell growth control. Curr Opin Cell Biol 10: 220-231, 1998.

22. Juliano R: Signal transduction by integrins and its role in the regulation of tumor growth. Cancer Metastasis Rev 13: 25-30, 1994.

23. Parise LV, Lee $J$ and Juliano RL: New aspects of integrin signaling in cancer. Semin Cancer Biol 10: 407-414, 2000.

24. Blystone SD: Integrating an integrin: a direct route to actin. Biochim Biophys Acta 1692: 47-54, 2004.

25. Ilic D, Kovacic B, Johkura K, et al: FAK promotes organization of fibronectin matrix and fibrillar adhesions. J Cell Sci 117: 177-187, 2004.

26. Schlaepfer DD, Hauck CR and Sieg DJ: Signaling through focal adhesion kinase. Prog Biophys Mol Biol 71: 435-478, 1999.

27. Schlaepfer DD, Hanks SK, Hunter T and van der GP: Integrinmediated signal transduction linked to Ras pathway by GRB2 binding to focal adhesion kinase. Nature 372: 786-791, 1994.

28. Schlaepfer DD and Mitra SK: Multiple connections link FAK to cell motility and invasion. Curr Opin Genet Dev 14: 92-101, 2004.

29. Schweyer S, Soruri A, Meschter O, et al: Cisplatin-induced apoptosis in human malignant testicular germ cell lines depends on MEK/ERK activation. Br J Cancer 91: 589-598, 2004.

30. Manohar A, Shome SG, Lamar J, Stirling L, Iyer V, Pumiglia K and Di Persio CM: $\{$ alpha\} 3 beta 1 integrin promotes keratinocyte cell survival through activation of a MEK/ERK signaling pathway. J Cell Sci 117: 4043-4054, 2004. 
31. Sonoda Y, Matsumoto Y, Funakoshi M, Yamamoto D, Hanks SK and Kasahara T: Anti-apoptotic role of focal adhesion kinase (FAK). Induction of inhibitor-of-apoptosis proteins and apoptosis suppression by the overexpression of FAK in a human leukemic cell line, HL-60. J Biol Chem 275: 16309-16315, 2000.

32. Sasaki H, Kotsuji F and Tsang BK: Caspase 3-mediated focal adhesion kinase processing in human ovarian cancer cells: possible regulation by $\mathrm{X}$-linked inhibitor of apoptosis protein. Gynecol Oncol 85: 339-350, 2002.

33. Chomczynski P: A reagent for the single-step simultaneous isolation of RNA, DNA and proteins from cell and tissue samples. Biotechniques 15: 532-537, 1993.

34. Koch S, Mayer F, Honecker F, Schittenhelm M and Bokemeyer C: Efficacy of cytotoxic agents used in the treatment of testicular germ cell tumours under normoxic and hypoxic conditions in vitro. Br J Cancer 89: 2133-2139, 2003.

35. Salvesen GS and Duckett CS: IAP proteins: blocking the road to death's door. Nat Rev Mol Cell Biol 3: 401-410, 2002.

36. Deveraux QL, Roy N, Stennicke HR, et al: IAPs block apoptotic events induced by caspase- 8 and cytochrome $\mathrm{c}$ by direct inhibition of distinct caspases. EMBO J 17: 2215-2223, 1998.

37. Nomura T, Mimata H, Yamasaki M and Nomura Y: Cisplatin inhibits the expression of $\mathrm{X}$-linked inhibitor of apoptosis protein in human LNCaP cells. Urol Oncol 22: 453-460, 2004.

38. Asselin E, Mills GB and Tsang BK: XIAP regulates Akt activity and caspase-3-dependent cleavage during cisplatin-induced apoptosis in human ovarian epithelial cancer cells. Cancer Res 61: 1862-1868, 2001.

39. Li J, Feng Q, Kim JM, et al: Human ovarian cancer and cisplatin resistance: possible role of inhibitor of apoptosis proteins. Endocrinology 142: 370-380, 2001.

40. Sun C, Cai M, Gunasekera AH, et al: NMR structure and mutagenesis of the inhibitor-of-apoptosis protein XIAP. Nature 401: 818-822, 1999.

41. Lotocki G, Alonso OF, Frydel B, Dietrich WD and Keane RW: Monoubiquitination and cellular distribution of XIAP in neurons after traumatic brain injury. J Cereb Blood Flow Metab 23: 1129-1136, 2003.

42. Ferreira CG, van der Valk P, Span SW, et al: Expression of $\mathrm{X}$-linked inhibitor of apoptosis as a novel prognostic marker in radically resected non-small cell lung cancer patients. Clin Cancer Res 7: 2468-2474, 2001.
43. Matsumiya T, Imaizumi T, Yoshida H, Kimura $H$ and Satoh K: Cisplatin inhibits the expression of X-chromosome-linked inhibitor of apoptosis protein in an oral carcinoma cell line. Oral Oncol 37: 296-300, 2001.

44. Du C, Fang M, Li Y, Li L and Wang X: Smac, a mitochondrial protein that promotes cytochrome c-dependent caspase activation by eliminating IAP inhibition. Cell 102: 33-42, 2000.

45. Srinivasula SM, Hegde R, Saleh A, et al: A conserved XIAPinteraction motif in caspase- 9 and $\mathrm{Smac} / \mathrm{DIABLO}$ regulates caspase activity and apoptosis. Nature 410: 112-116, 2001.

46. Verhagen AM and Vaux DL: Cell death regulation by the mammalian IAP antagonist Diablo/Smac. Apoptosis 7: 163-166, 2002.

47. Verhagen AM, Ekert PG, Pakusch M, et al: Identification of DIABLO, a mammalian protein that promotes apoptosis by binding to and antagonizing IAP proteins. Cell 102: 43-53, 2000.

48. De Graaf AO, De WT and Jansen JH: Inhibitor of apoptosis proteins: new therapeutic targets in hematological cancer? Leukemia 18: 1751-1759, 2004.

49. Shiozaki EN, Chai J, Rigotti DJ, et al: Mechanism of XIAPmediated inhibition of caspase-9. Mol Cell 11: 519-527, 2003.

50. Takemura Y, Kobayashi H, Miyachi H, Hayashi K, Sekiguchi S and Ohnuma T: The influence of tumor cell density on cellular accumulation of doxorubicin or cisplatin in vitro. Cancer Chemother Pharmacol 27: 417-422, 1991.

51. Frisch SM, Vuori K, Ruoslahti E and Chan-Hui PY: Control of adhesion-dependent cell survival by focal adhesion kinase. J Cell Biol 134: 793-799, 1996.

52. Hungerford JE, Compton MT, Matter ML, Hoffstrom BG and Otey CA: Inhibition of pp $125 \mathrm{FAK}$ in cultured fibroblasts results in apoptosis. J Cell Biol 135: 1383-1390, 1996.

53. Crouch DH, Fincham VJ and Frame MC: Targeted proteolysis of the focal adhesion kinase pp $125^{\text {FAK }}$ during c-myc-induced apoptosis is suppressed by integrin signalling. Oncogene 12: 2689-2696, 1996

54. Sasaki H, Sheng Y, Kotsuji F and Tsang BK: Down-regulation of X-linked inhibitor of apoptosis protein induces apoptosis in chemoresistant human ovarian cancer cells. Cancer Res 60: 5659-5666, 2000. 